\title{
An Investigation on Cynicism and Environmental Self-Efficacy as Predictors of Pro-Environmental Behavior
}

\author{
Juneman Abraham', Murty Magda Pane' ${ }^{2}$, Rina Patriana Chairiyani ${ }^{2}$ \\ ${ }^{1}$ Department of Psychology, Bina Nusantara University, Jakarta, Indonesia \\ ${ }^{2}$ Character Building Development Center, Bina Nusantara University, Jakarta, Indonesia \\ Email: juneman@binus.ac.id, murty.pane@gmail.com, patriana rina@yahoo.com
}

Received 26 January 2015; accepted 10 February 2015; published 12 February 2015

Copyright (C) 2015 by authors and Scientific Research Publishing Inc.

This work is licensed under the Creative Commons Attribution International License (CC BY). http://creativecommons.org/licenses/by/4.0/

(c) (7) Open Access

\begin{abstract}
Environmental problem is one of the biggest problems that threatens human life. Human behavior has long been known to play an important role in maintaining and improving environmental sustainability. Psychological studies investigating predictors of pro-environmental behavior have been carried out, but no studies link it with cynicism and self-efficacy simultaneously. This study design was predictive correlational and data analysis technique employed was multiple linear regression analysis. Participants of this study were 205 undergraduate students in Jakarta (132 males, 73 females; $M_{\text {age }}=19.68$ years old; $S D_{\text {age }}=0.849$ years) taken using convenience sampling technique. This study found that cynicism and environmental self-efficacy are able to predict proenvironmental behavior in positive directions. This study suggests revising the measurement instrument of cynicism.
\end{abstract}

\section{Keywords}

Cynicism, Self-Efficacy, Pro-Environmental Behavior

\section{Introduction}

Throughout the history of environmental science, there are always debates regarding the causes of environmental crisis; whether it is caused truly by natural dynamics, supernatural dynamics, or fully in the hand and/or control of human (Rudiak-Gould, 2013).Views regarding the dichotomy between human (as well as their dimensions) and nature as well as the belief regarding "the way the world works" (whether the world is working "just”) also contributes to the debate, and culture even ideology plays an important role (Rudiak-Gould, 2013). However, 
on top of all those debates, what cannot be denied, based on ecological approach, is the fact that human is an entity that cannot be separated if we are talking about environmental crisis and saving effort.

On a psychological level, one human variable that is suspected of contributing toward pro-environment behavior is cynicism. Zhou (2015: p. 62) recently stated, "The other side of popular attitudes toward environmental issues, environmental skepticism, has long been overlooked, however. Environmental skepticism can be defined as doubt about the authenticity or severity of environmental problems". The word "cynicism" has often been used interchangeably with "skepticism” (e.g., Matthes \& Wonneberger, 2014; Vice, 2011). Cynicism is "a habitual and cultivated attitude of skepticism or distrust regarding people's professed values and motivations, or their strength and nobility of character" (Vice, 2011: p. 173).

Menke (2004: p. 16) described the similarities and differences between cynicism and skepticism as follows:

"Both describe doubt. Skepticism is often attached to the word 'healthy', as in 'healthy skepticism'. Cynicism drifts into bitter passivity and creates a 'victim' attitude."

There have been researches that study the sources of skepticism. Zhou's study (2015) found those sources, namely knowledge, education, religious values, belief in science, and attention to other issues outside of environmental issues. In this present study, what is emphasized is the consequence of cynicism toward pro-environmental behavior.

Roberts (2011) proposed there are three types of "sustainability cynic", namely the non-believer (which considers environmental issues as deception by certain parties, and cannot be convinced through any scientific research), the hard-boiled capitalist (which considers environmental issues as an inherent and inevitable issues of the world that is full of games and the spirit of pragmatism and competition), and the environmental elitist (which admits that there is a need for a movement to save the environment, but does not believe in the sincerity of authoritative and big institutions having "sophisticated technology", and would rather let small communities handle the environmental issues).

So far, researches which study cynicism always linked it with social situation, both interpersonal, organizational, and intergroup (e.g. Eisinger, 1999; Kruger \& Gilovich, 1999; Levy, 2005; McClough, Rogelberg, Fisher, \& Bachiochi, 1998; Mantere \& Martinsuo, 2001). However, there is rarely any study that linked it with the natural environmental settings. Peter Jacques (as cited in Allison, 2010) showed the existence of "environmental skepticism" construct that can cause human to ignore their responsibility toward non-human entity and even "detach themselves from nature". Furthermore, in advertising, it has already been known that cynicism toward general objects is linked with negative behavior toward specific object. "People who are generally cynical about advertising will also react negatively to green ads. The reason is that people may use their general ad skepticism as a cure or proxy to evaluate particular types of ads such as green ads.” (Matthes \& Wonneberger, 2014: pp. 119-120). Gronewold, Burnett, and Meister (2012) through empirical-qualitative research found that the cynical view toward nature (in this case: weather) correlates negatively with the participative behavior of farmers in nature (in this case: land) conservation program.

This research uses the same logic that is in line with those propositions; that is people who are in general cynical about human behavior will have a negative pro-environmental attitude and behavior. This research provides a theoretical contribution by making the general cynicism as a predictor toward behavior related to the natural environment.

Another rationale from this research that makes cynicism as a predictor of pro-environmental behavior is that cynicism hinders cooperation with other people and communities, whereas environmental issues are often a complex and tremendous issues that require cooperation (Juneman \& Pane, 2013). Chiu (2005) stated that cynicism can penetrate the social domain lowering efficacy and participation in community actions that aims to increase the common good.

In the context of law, Kirk and Matsuda (2011) found that cynicism make individuals view law and its enforcement agency as illegitimate, unresponsive, and insufficient in ensuring public safety. As a consequence, these individuals will not obey the law and do not endorse law enforcement. Crime increases in the community of cynics. In relation to pro-environment behavior, this has serious implication. Cynicism can make individuals oppose regulation that support environmental maintenance, conservation, and ecological sustainability. In other words, if the world in controlled by cynics, then it is hypothesized that environmental destruction will be inevitable.

Kruger and Gilovich (1999) found through experimental research that cynics have a bias in evaluating other people’s responsibility. They place a bigger responsibility on the out-group as compared to their in-group. As 
we know, environmental issue is a shared problem that must be handled together. Problems arise because cynical people consider their contribution to be more than they actually are (overestimation bias). They are unfair in allocating the burden that must be carried by other individuals. "If people consistently overestimate their own contributions, they may feel they are doing more than their share-and that others are doing less than theirs" (Kruger \& Gilovich, 1999: p. 751). This condition is prone to social conflict and distrust between one another. Cooperation, in order to repair the environment, becomes less likely. The result is a behavior that does not advocate environmental sustainability but rather an apathy and even destruction.

In political context, Levy (2005) is of the opinion that cynicism is dangerous, not because cynics are suspicious of the motives behind the expression of political ideals, but because cynicism creates "resentiment", that uses imperfect reality as a justification to participate in a worsening political situation (trapping themselves in melancholy) rather than seeing imperfection as a motivational source to change the political situation. Cynicism is essentially "passive activity" (Levy, 2005: p. 349). When it is related to environmental issues, cynical views will see that environmental issue as a huge problem that is impossible to handle, based on the fact that efforts that have been programmed and conducted so far have not solved the issues; rather environmental issues become bigger and wider in their scope and complexity. In following Levy's logic, the danger of cynicism is not that it will question campaigns and messages that remind us the danger of global warming, and so forth. However, the cynics' frustration of seeing the problem will tend to make them become passive observers that do not put any effort to improve the local, let alone global environment.

Based on the rationales mentioned above, the first hypothesis of this research (H1) is: "The higher an individual's cynicism, the lower his/her pro-environmental behavior”.

Another psychological variable that is suspected to influence pro-environmental behavior is environmental self-efficacy which is "beliefs concerning their capability to act in order to limit environmental degradation" (Wu \& Mweemba, 2010: p. 736). The suggested correlation is a positive correlation. The mechanism is that selfefficacy increases the internal motivation and further increases pro-environment behavior (Tabernero \& Hernández, 2011). What differentiates this research with the research of Tabernero and Hernández (2011) is that they focused on one example of pro-environmental behavior, namely recycling behavior; whereas this research gathers various examples of pro-environmental behavior that are then scored into one composite score that is the index of the dependent variable. Based on the rationale mentioned above, the second hypothesis of this research (H2) is: "The higher an individual's environmental self-efficacy, the higher his/her pro-environmental behavior”.

\section{Methods}

\subsection{Design and Participant}

This research used predictive correlational design, with cynicism and environmental self-efficacy as the predictor variables and pro-environmental behavior as the criterion variable. Participants of this research were 205 undergraduate students (132 males, 73 females; $M_{\text {age }}=19.68$ years old; $S D_{\text {age }}=0.849$ years) of Bina Nusantara University in Jakarta, the capital of Indonesia, taken using convenience sampling technique. Data were processed using multiple linear regression analysis done by SPSS 22 for Windows.

Participants were given three psychological scales in Indonesian that measure pro-environmental behavior, cynicism, and environmental self-efficacy. A pilot study is conducted to test the validity and reliability of all the scales with 70 participants $\left(M_{\text {age }}=19.71\right.$ year olds; $S D_{\text {age }}=0.769$ years). The criteria to determine the validity and reliability of the measuring scales are the corrected item-total correlations index that is greater than or equal to 0.25 , and Cronbach's Alpha index that is greater than or equal to 0.60 .

\subsection{Instrument}

Pro-environmental behavior is measured on a scale adapted from Dono, Webb, and Richardson (2010), Videras, Owen, Conover, and Wu (2012), as well as Markle (2013). This scale consists of 26 items. Example of the items are: 1) "I make a special effort to buy fruits and vegetables frown without pesticides"; 2) "I make a special effort to buy paper and plastic products that are made from recycled materials"; 3) "I would be willing to accept cuts in my standard of living to protect the environment"; 4) "In the last 1 year, I have personally worked with others in my local community to solve an environmental problem”; 5) "In the last 1 year, I have personally volunteered 
for an environmental project”; 6) I have voted for a candidate in a political election, at least in part, because he or she was in favour of strong environmental protection"; 7) "During the past year, I have walked or cycled instead of driving"; 8) "During the past year, I have used public transportation"; 9) "During the past year, I have decreased the amount of beef I consume"; 10) "I switch off standby modes of appliances or electronic devices"; and 11) "I turn off the lights when leaving a room". This scale has six response options, from "Never" (score of 1) to "Always" (score of 6). The result of the validity and reliability test showed that this scale is reliable (Cronbach's Alpha $=0.920)$ and valid (corrected item total correlations $=0.297-0.754$ ) by eliminating 4 of the items.

Cynicism was measured with a cynicism scale adapted from Turner and Valentine (2001). This scale consists of 11 items. Example of the items are: 1) "To a greater extent than most people realize, our lives are governed by plots hatched in secret by politicians and big businesses"; 2) "When someone does me a favor, I know they will expect one in return"; 3) "Outside of my immediate family, I don't really trust anyone”; and 4) "Big companies make their profits by taking advantage of working people". This scale has six response options, from "Strongly Disagree" (score of 1) to "Strongly Agree" (score of 6). The result of the validity and reliability test showed that this scale is reliable (Cronbach's Alpha $=0.742$ ) and valid (corrected item total correlations $=0.287$ 0.621 ) by eliminating 3 of the items.

Environmental self-efficacy was measured on a scale adapted from Wu and Mweemba (2010). This scale consists of 4 items. Examples of those items are: 1) I believe in my ability to reduce environmental degradation around me; 2) I believe in my ability to reduce environmental degradation in my city; and 3) I believe in my ability to influence policy makers to protect the environment. This scale has six response options, from "Strongly Disagree" (score of 1) to "Strongly Agree" (score of 6). The result of the validity and reliability test showed that this scale is reliable (Cronbach’s Alpha $=0.780)$ and valid (corrected item total correlations $=0.546-0.606)$ without eliminating any item.

\subsection{Procedure}

The research data were collected through a questionnaire consisting of psychological scales described above. This research was conducted throughout April to November 2014. The authors came into the classrooms which organized Character Building courses at Bina Nusantara University, Jakarta, Indonesia. The whole process of this research had gone through the approval of the Vice Rector of Research \& Technology Transfer-Bina Nusantara University and been acknowledged through Letter No. 015.A/VR.RTT/IV/2014.

\section{Results}

The distribution of participants based on their study program is as follows: Information Technology (47), Information System (35), Visual Communication Design (23), Accounting (21), Architecture (10), International Business Management (10), International Relations (8), Civil Engineering (8), Management (6), Marketing Communication (6), Hotel Management (4), Chinese Literature (4), Entrepreneurship (3), Industrial Engineering (3), Broadcasting (2), Psychology (2), Public Relations (2), and others (11).

Normality test showed that the data are distributed around the normal trend line (see Figure 1). Multicollinearity test showed that the data are free of multicolinearity (VIF $<10$, Tolerance $>0.1$ ) (Table 1 ). Heteroscedasticity test showed that no heteroscedasticity occurred (no pattern on the scatterplot and the data are distributed above and below 0) (see Figure 2).

Multiple linear regression analysis shows that $R^{2}=0.239, F(2,204)=31.794, p=0.000$. It is found that cynicism $(\beta=0.212, p<0.01)$ and environmental self-efficacy $(\beta=0.420, p<0.01)$ significantly positively predict pro-environmental behavior (see Table 1 ).

Table 1. Multiple linear regression analysis predicting pro-environmental behavior $(n=205)$.

\begin{tabular}{cccccccc}
\hline Variable & $B$ & $S E B$ & $\beta$ & $t$ & $p$ & Tolerance & VIF \\
\hline Cynicism & 0.647 & 0.189 & 0.212 & 3.431 & 0.001 & 0.989 & 1.011 \\
$\begin{array}{c}\text { Environmental } \\
\text { Self-Efficacy }\end{array}$ & 2.084 & 0.306 & 0.420 & 6.800 & 0.000 & 0.989 & 1.011 \\
\hline
\end{tabular}

Note: $R^{2}=0.239 ; S E=$ Standard Error. 


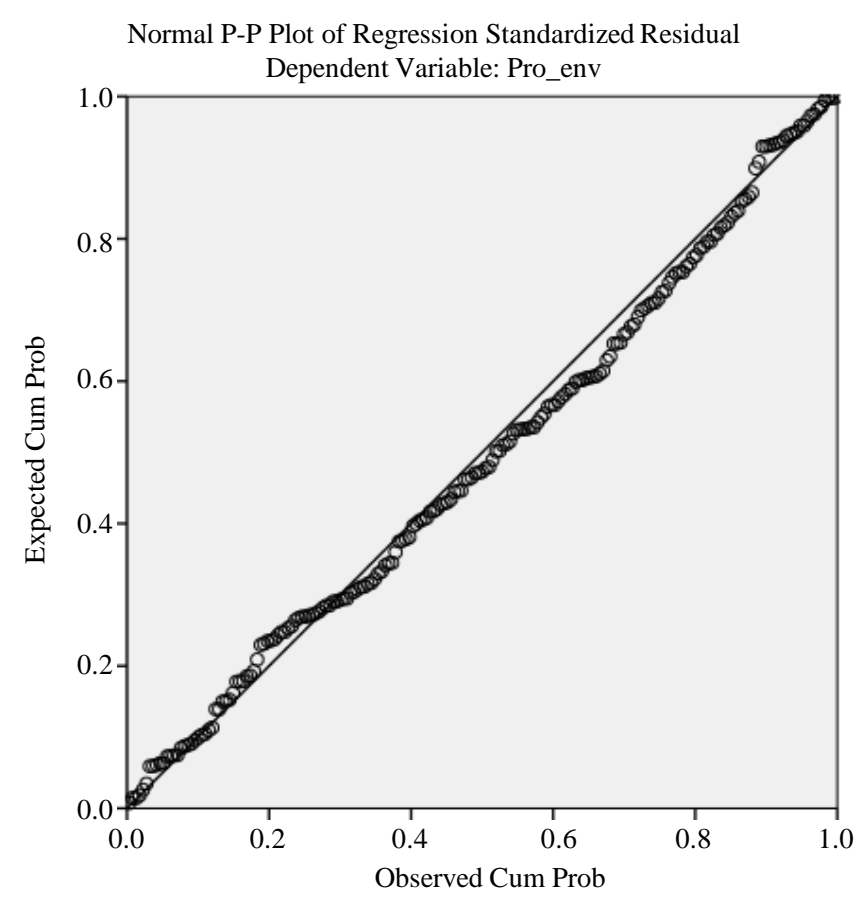

Figure 1. Normality test.

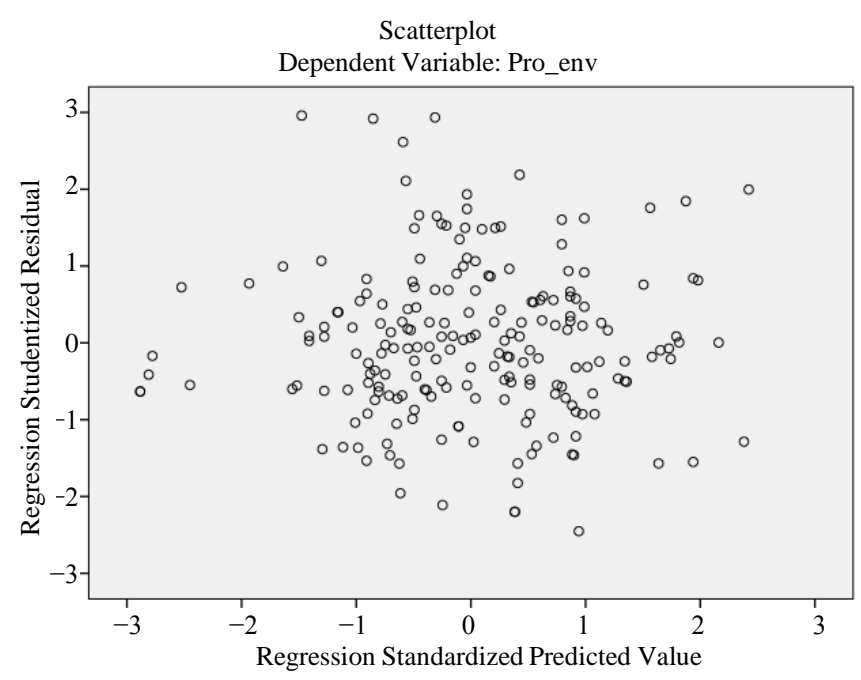

Figure 2. Heteroscedasticity test.

\section{Discussion}

This research found that cynicism is able to predict pro-environmental behavior in a positive direction. This finding does not support H1that suggests a negative correlation.

Tsay, Shu, and Bazerman (2011) stated that cynicism is the opposite of naiveté behavior. In the naiveté behavior, an individual believes other people or parties without considering that they have private interest and strategy. On the other hand, in cynicism, one's own prejudice hinders the prosperity that he/she should have if he/she is not cynical; in other words, the individual has negative views and distrust to other people's intention and motive; that is "dysfunctional" (Tsay, Shu, \& Bazerman, 2011). So, cynicism is more than just distrust (Eisinger, 1999). Kruger and Gilovich (as cited in Tsay, Shu, \& Bazerman, 2011) described people with cynicism as people that believe that other people or parties will provide a bias evaluation or estimation when assessing their contribution on the "joint outcomes". However, cynicism in an optimum level (not too high; or can be called: 
healthy cynicism) in a person indicates that the person is able to take other people's side (perspective-taking). When related to the result of this research, the positive correlation between cynicism and pro-environment behavior can be explained as follows: Pro-environmental behavior resulted from cynicism on a certain level that makes it possible for participants of this research to feel the loss of the damaged environment.

Although cynics have no empathy due to their behaviors which are based on self-interest, Chowdhury and Fernando (2014) found that cynicism positively correlate with "no harm, no foul" behavior (i.e. behavior that indirectly harm others) via moral disengagement. Meaning, there are some cynics that hold on to the "as long as it does not harm the environment” principle (Krages II, 2000: p. 67). This research had not sensitively differentiated between people that perform anti-environment behavior and people that perform "no harm, no foul" environment behavior. People that are not anti-environment are categorized as pro-environment (which include "no harm, no foul" behavior), but not necessarily so. This is possibly the reason that explains the positive correlation found by this research.

Another researcher, Eisinger (1999), proposed a fact that American citizens that are considered "cynics" are actually still participative politically, religious, even altruistic. He explained that this reality is possible if the citizen has two different attitudes toward two institutions within themselves, for example the belief in Church/ Religion (which encourage them to have positive quality in public life) and at the same time distrust the government. When related to the result of this research, the positive correlation between cynicism and pro-environment behavior can be explained as follows: participants of this research are students that show loyalty toward the application of their knowledge. All students in this research have indeed taken Character Building courses provided by Character Building Development Center of which pro-environmental behavior is an integral material. However, at the same time, cynicism that can be resulted from idealism and critical thinking from academic culture can also become a living part of the students.

Helm (2004) showed a unique fact based on his empirical research that cynical consumers actually have a strong loyalty to certain brands from a small number of companies that they trust. Helm explained that if cynicism is overcome, trust is possible. In this case, previous experience toward those companies plays a role. When related to the result of this research, positive correlation between cynicism and pro-environment behavior can be explained as follows: participants have directly or indirectly experienced some advantages from the behaviors that support the environment hence their cynicism has less influence in preventing pro-environmental behavior. They are going beyond their cynicisms. The participants become stronger in endorsing the behavior. This "contrast effect" is influenced by prior positive experience from environmentally friendly behavior.

McClough et al. (1998) showed their empirical research result that in the change process, cynicism plays a positive role in the early stages. It is indicated by cynical employees who tend to give comments that are more descriptive and useful for organization development. McClough et al. (1998: pp. 32-33) clarified it:

“...a cynical individual must believe that things can be better, must regard initiative as futile, and must attribute failure to the system as a whole... Cynicism is paradoxical in that the cynic must hold both positive feelings (improvability of the organization) and negative feelings (inevitable failure of change efforts) simultaneously... (and it) may cause cynical employees to participate in change efforts in unexpected ways.”

Cynicism positively correlates with quality responses that relate to organization quality. This is because cynicism is formed from a high expectation that result in disappointment and frustration. Those expectations come from the notion of "how things should actually work". When related to the result of this research, positive correlation between cynicism and pro-environment behavior can be explained as follows: environmental changes are social changes that require pro-environmental behavior. Various environmental issues are unsolvable, and many of the usual solutions being offered do not show a significant result. In this case, it requires an offer that is rich, innovative, and creative to help solve the issues. It is at this point, cynics are needed, because they have new ideas that may not be thought of by people in general and they are willing to express them if asked openly.

In organizational context, Mantere and Martinsuo (2001: p. 5) define cynicism as:

"1) a belief that there is a gap between desired and observed organizational identity; 2) a negative affect toward the organization or organizational change (strategy); and 3) tendencies to disparaging and/or critical behaviors toward the organization that are consistent with those beliefs and affect."

They differentiated between "general cynicism" and "strategy cynicism". People with general cynicism express many negative emotions, such as anger and accusation, also negative coping behavior, and do not care of strategy to create a better condition. On the other hand, strategy cynicism expresses irony but do so through humor, have realistic views, perform positive coping, and ready with strategic knowledge, ideas, and skills to solve 
the problem. Mantere and Martinsuo (2001) proposed an interesting fact that the concept of cynicism is actually rooted in ancient Greek culture, an in this case, it is in line with "strategy cynicism". The connotation of the word "cynics" is not as negative then as it is now. Cynics are people with the highest wisdom and virtue that questions and criticize the values of the majority, law and culture (Copleston, as cited in Mantere \& Martinsuo, 2001).

In ancient Greek, especially during the times of Diogenes, cynicism is a school of post-Socratic practical philosophy that independently questioned directly (without metaphor and biased words or actions) social, cultural, institutional, and political discourses, and that radically acted (in every respect, with all the effort and power) to improve situations, and hence surprising the observing public (Sverdiolas, 2008). Cynics were the proponents of reformation aimed at enhancing the well-being of individuals and society (Govier, 1997). They were called antiestablishment people. However, what is meant by "anti" here is not "against" but "seek alternative forms sufficient to improve the situation". This is described by Bayan (2013), as follows:

"Cynicism, after all, springs not from cruelty or viciousness, but from precisely the opposite: a fatal love of virtue. If we were mere realists, we'd have no need for cynicism; the world would never disappoint us because we'd expect so little of it. But the best cynics are still idealists under their scarred hides. We wanted the world to be a better place, and we can't shrug off the disappointment when it lets us down.”

When related to the result of this research, the positive correlation between cynicism and pro-environment behavior can be explained as follows: cynical people might be critical people that questioned old ways in handling environmental issues. They may be committed to pro-environment behavior, but about the "how", they are continuously searching and may already have alternative ideas in their head. They have a great understanding of the things that are considered as the essence of the issues, and hence they have different strategies from the majority of people. In other words, they are categorized as "strategic cynicism" rather than "general cynicism" according to Mantere and Martinsuo (2001).

This study found a positive correlation between environmental self-efficacy and pro-environmental behavior as hypothesized (H2 was supported by empirical data). Saribas, Teksoz, and Ertepinar (2014) stated that high self-efficacy that someone has will make him/her does more persistent work compared with people with low self-efficacy. In addition, they found that environmental self-efficacy beliefs related to environmental concerns. Oneal et al. (2012) found that no measurement research related to environmental self-efficacy, and therefore the results of their psychometric research to be important in the field of environmental psychology. This present study utilized environmental self-efficacy as a predictor variable of pro-environmental behavior, and confirmed the robustness of self-efficacy in a specific field as a classic predictor of behavior in that field.

\section{Conclusion}

In this research, cynicism was found to play a role in predicting pro-environment behavior in students. However, not as hypothesized, it resulted in a positive predictive correlation. The more cynical the student, the more proenvironment they become. We need to be careful in interpreting cynicism, because cynicism actually has positive consequences, in line with the original understanding of psychological mechanisms of cynicism in ancient Greek. This was indeed found among undergraduate students in Jakarta, Indonesia.

The limitation of this study is that it did not distinguish between different types of cynicism, and therefore could not sensitively capture the various conditions and dynamics of cynicism. In addition, this research did not investigate the possible mediating and/or moderating variables that might play roles in predicting pro-environmental behavior from cynicism. The recommendation that can be given is to revise the measuring instruments cynicism as well as to integrate other environmental psychological related variables in further researches.

Environmental self-efficacy can also predict pro-environmental behavior.

\section{References}

Allison, J. E. (2010). Environmental Skepticism: Ecology, Power, and Public Life (Review). Global Environmental Politics, 10, 131-133. http://dx.doi.org/10.1162/GLEP_r_00036

Bayan, R. (2013). All about Cynicism. http://richardbayan.typepad.com/the_cynics_sanctuary/what-is-cynicism.html

Chiu, C. C. H. (2005). Cynicism about Community Engagement in Hong Kong. Sociological Spectrum, 25, 447-467. http://dx.doi.org/10.1080/027321790947207

Chowdhury, R. M. M. I., \& Fernando, M. (2014). The Relationships of Empathy, Moral Identity and Cynicism with Con- 
sumers’ Ethical Beliefs: The Mediating Role of Moral Disengagement. Journal of Business Ethics, 124, 677-694. http://dx.doi.org/10.1007/s10551-013-1896-7

Dono, J., Webb, J., \& Richardson, B. (2010). The Relationship between Environmental Activism, Pro-Environmental Behaviour and Social Identity. Journal of Environmental Psychology, 30, 178-186.

http://dx.doi.org/10.1016/j.jenvp.2009.11.006

Eisinger, R. M. (1999). Cynical America? Misunderstanding the Public’s Message. The Public Perspective, April/May, 4548.

Govier, T. (1997). Social Trust and Human Communities. Montreal, QC: McGill Queens University Press.

Gronewold, K. L., Burnett, A., \& Meister, M. (2012). Farmers’ Cynicism toward Nature and Distrust of the Government: Where Does that Leave Conservation Buffer Programs? Applied Environmental Education \& Communication, 11, 18-24. http://dx.doi.org/10.1080/1533015X.2012.728061

Helm, A. (2004). Cynics and Skeptics: Consumer Dispositional Trust. Advances in Consumer Research, 31, 345-351.

Juneman, \& Pane, M. M. (2013). Apathy towards Environmental Issues, Narcissism, and Competitive View of the World. Procedia-Social and Behavioral Sciences, 101, 44-52. http://dx.doi.org/10.1016/j.sbspro.2013.07.177

Kirk, D. S., \& Matsuda, M. (2011). Legal Cynicism, Collective Efficacy, and the Ecology of Arrest. Criminology, 49, 443472. http://dx.doi.org/10.1111/j.1745-9125.2011.00226.x

Krages II, B. P. (2000). Total Environmental Compliance: A Practical Guide for Environmental Professionals. Boca Raton, FL: Lewis Publishers.

Kruger, J., \& Gilovich, T. (1999). “Naive Cynicism” in Everyday Theories of Responsibility Assessment: On Biased Assumptions of Bias. Journal of Personality and Social Psychology, 76, 743-753. http://dx.doi.org/10.1037/0022-3514.76.5.743

Levy, M. A. (2005). Cynicism, Social Epistemic, and the Institutional Context of College Composition. Journal of Antimicrobial Chemotherapy, 25, 347-370.

Mantere, S., \& Martinsuo, M. (2001). Adopting and Questioning Strategy: Exploring the Roles of Cynicism and Dissent. Proceedings of the 17th EGOS-European Group for Organization Studies Colloquium, Lyon, 5-7 July 2001, 1-25.

Markle, G. L. (2013). Pro-Environmental Behavior: Does It Matter How It’s Measured? Development and Validation of the Pro-Environmental Behavior Scale (PEBS). Human Ecology, 41, 905-914. http://dx.doi.org/10.1007/s10745-013-9614-8

Matthes, J., \& Wonneberger, A. (2014). The Skeptical Green Consumer Revisited: Testing the Relationship between Green Consumerism and Skepticism toward Advertising. Journal of Advertising, 43, 115-127. http://dx.doi.org/10.1080/00913367.2013.834804

McClough, A. C., Rogelberg, S. G., Fisher, G. G., \& Bachiochi, P. D. (1998). Cynicism and the Quality of an Individual’s Contribution to an Organizational Diagnostic Survey. Organizational Development Journal, 16, 31-41.

Menke, J. M. (2004). Skepticism and Cynicism. Dynamic Chiropractic, 22, 16.

Oneal, G., Odom-Maryon, T., Postma, J., Hill, W., \& Butterfield, P. (2012). The Household Risk Perception Instrument and the Self-Efficacy in Environmental Risk Reduction Instrument: Psychometric Testing Using Principal Component Analysis. Journal of Advanced Nursing, 69, 2107-2115. http://dx.doi.org/10.1111/jan.12065

Roberts, J. M. (2011). 3 Species of Environmental Cynicism. http://ecoopportunity.net/2011/06/3-species-of-environmental-cynicism/

Rudiak-Gould, P. (2013). Cross-Cultural Insights into Climate Change Skepticism. Bulletin of the American Meteorological Society, 94, 1707-1713. http://dx.doi.org/10.1175/BAMS-D-12-00129.1

Saribas, D., Teksoz, G., \& Ertepinar, H. (2014). The Relationship between Environmental Literacy and Self-Efficacy Beliefs toward Environmental Education. Procedia-Social and Behavioral Sciences, 116, 3664-3668. http://dx.doi.org/10.1016/j.sbspro.2014.01.820

Sverdiolas, A. (2008). Cynicism: A Lithuanian Version. Athena: Philosophical Studies. http://lkti.lt/athena/pdf/3/82-97.pdf

Tabernero, C., \& Hernández, B. (2011). Self-Efficacy and Intrinsic Motivation Guiding Environmental Behavior. Environment and Behavior, 43, 658-675. http://dx.doi.org/10.1177/0013916510379759

Tsay, C. J., Shu, L. L., \& Bazerman, M. H. (2011). Naiveté and Cynicism in Negotiations and Other Competitive Contexts. The Academy of Management Annals, 5, 495-518. http://dx.doi.org/10.1080/19416520.2011.587283

Turner, J. H., \& Valentine, S. R. (2001). Cynicism as a Fundamental Dimension of Moral Decision-Making: A Scale Development. Journal of Business Ethics, 34, 123-136. http://dx.doi.org/10.1023/A:1012268705059

Vice, S. (2011). Cynicism and Morality. Ethical Theory and Moral Practice, 14, 169-184. http://dx.doi.org/10.1007/s10677-010-9250-y

Videras, J., Owen, A. L., Conover, E., \& Wu, S. (2012). The Influence of Social Relationships on Pro-Environment Beha- 
J. Abraham et al.

viors. Journal of Environmental Economics and Management, 63, 35-50. http://dx.doi.org/10.1016/j.jeem.2011.07.006

Wu, H., \& Mweemba, L. (2010). Environmental Self-Efficacy, Attitude and Behavior among Small Scale Farmers in Zambia. Environment, Development and Sustainability, 12, 727-744. http://dx.doi.org/10.1007/s10668-009-9221-4

Zhou, M. (2015). Public Environmental Skepticism: A Cross-National and Multilevel Analysis. International Sociology, 30, 61-85. http://dx.doi.org/10.1177/0268580914558285 
Scientific Research Publishing (SCIRP) is one of the largest Open Access journal publishers. It is currently publishing more than 200 open access, online, peer-reviewed journals covering a wide range of academic disciplines. SCIRP serves the worldwide academic communities and contributes to the progress and application of science with its publication.

Other selected journals from SCIRP are listed as below. Submit your manuscript to us via either submit@scirp.org or Online Submission Portal.
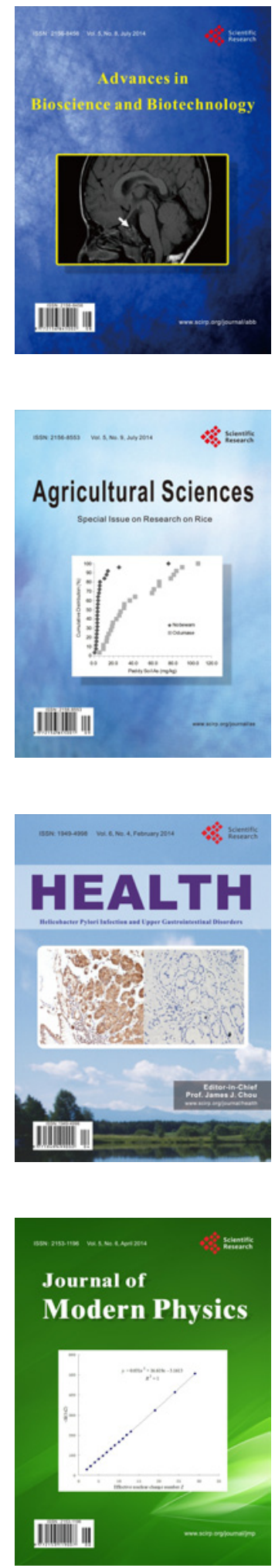
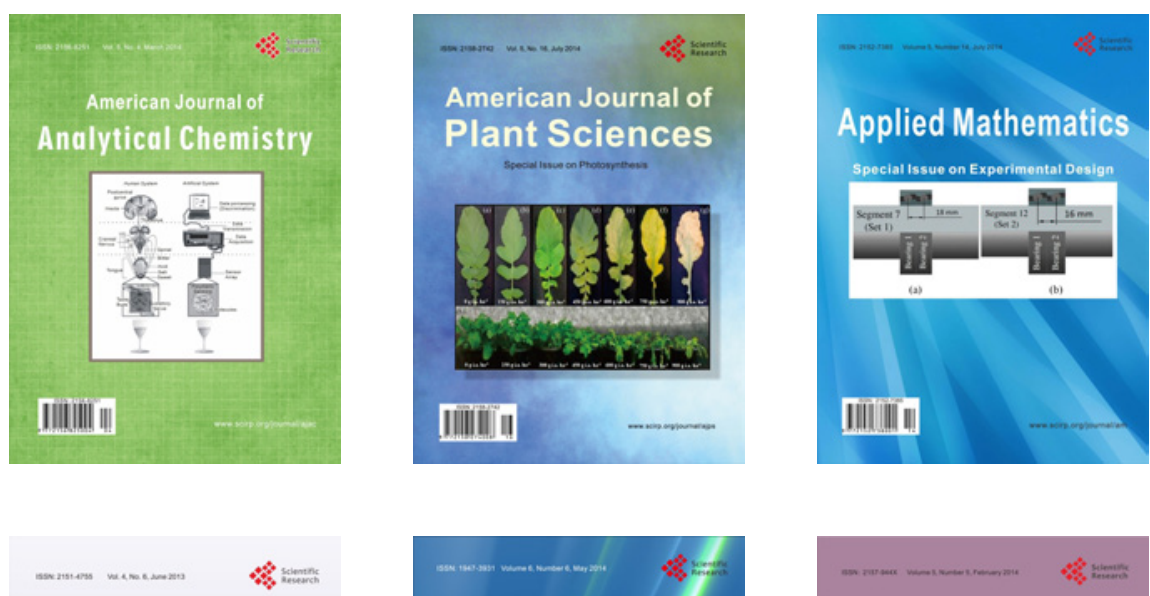

Creative Education
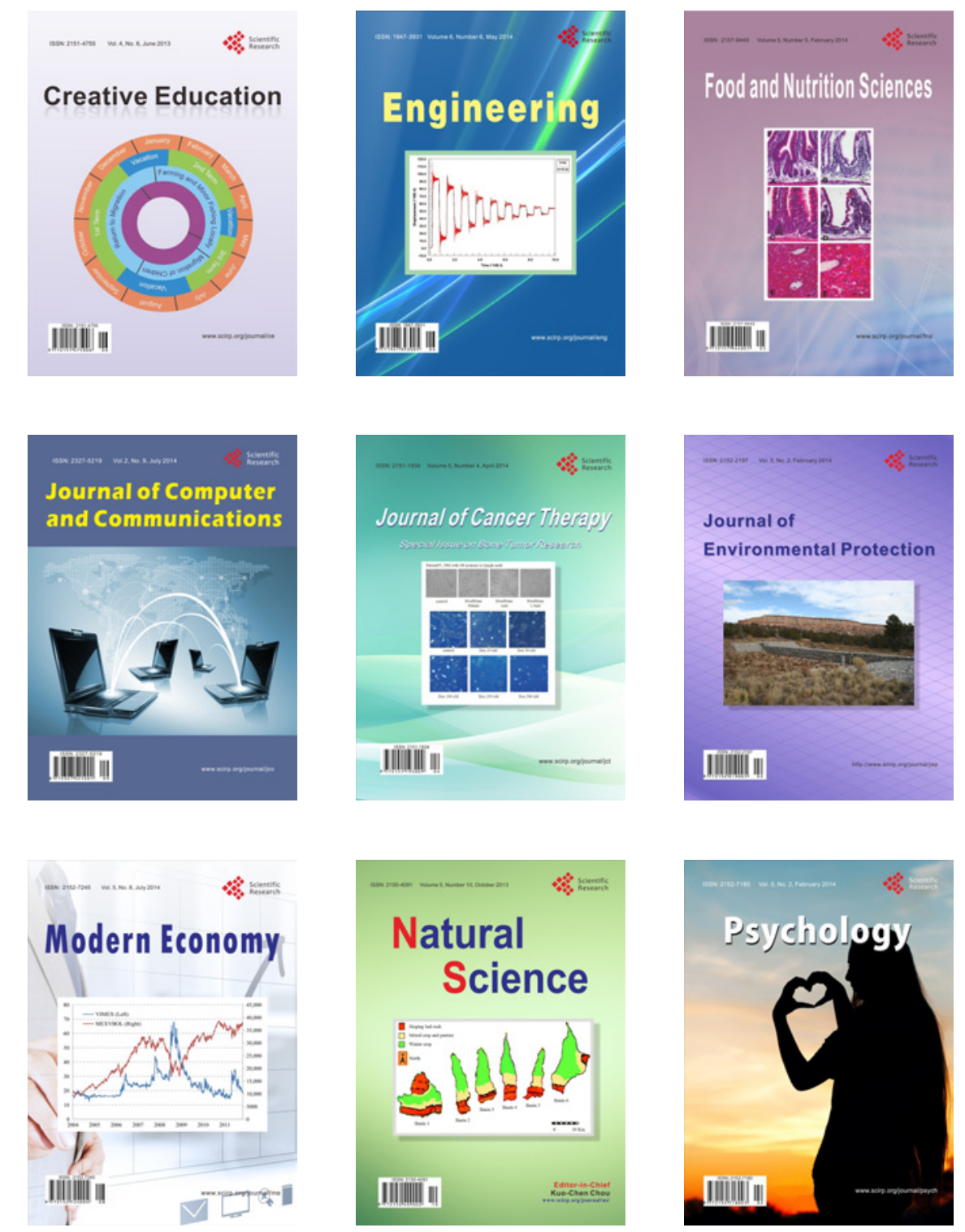